\title{
BMJ Open Caffeine prophylaxis to improve intermittent hypoxaemia in infants born late preterm: a randomised controlled dosage trial (Latte Dosage Trial)
}

\author{
Elizabeth Anne Oliphant (D) , ${ }^{1,2}$ Christopher J D McKinlay, ${ }^{3,4}$ David G McNamara, ${ }^{5}$ \\ Jane Marie Alsweiler (D) ${ }^{1}$
}

To cite: Oliphant EA, McKinlay CJD, McNamara DG, et al. Caffeine prophylaxis to improve intermittent hypoxaemia in infants born late preterm: a randomised controlled dosage trial (Latte Dosage Trial). BMJ Open 2020;10:e038271. doi:10.1136/ bmjopen-2020-038271

- Prepublication history for this paper is available online. To view these files, please visit the journal online (http://dx.doi org/10.1136/bmjopen-2020038271).

Received 05 March 2020 Revised 16 July 2020

Accepted 08 September 2020

Check for updates

(C) Author(s) (or their employer(s)) 2020. Re-use permitted under CC BY-NC. No commercial re-use. See rights and permissions. Published by BMJ.

For numbered affiliations see end of article.

Correspondence to Elizabeth Anne Oliphant; e.oliphant@auckland.ac.nz

\section{ABSTRACT}

Introduction Infants born late preterm (34+0 to $36+6$ weeks' gestational age) have frequent episodes of intermittent hypoxaemia compared with term infants. Caffeine citrate reduces apnoea and intermittent hypoxaemia and improves long-term neurodevelopmental outcomes in infants born very preterm and may have similar effects in late preterm infants. Clearance of caffeine citrate increases with gestational age and late preterm infants are likely to need a higher dose than very preterm infants. Our aim is to determine the most effective and best-tolerated dose of caffeine citrate to reduce transient intermittent hypoxaemia events in late preterm infants.

Methods and analysis A phase IIB, double-blind, fivearm, parallel, randomised controlled trial to compare the effect of four doses of oral caffeine citrate versus placebo on the frequency of intermittent hypoxaemia. Late preterm infants will be enrolled within 72 hours of birth and randomised to receive $5,10,15$ or $20 \mathrm{mg} / \mathrm{kg} /$ day caffeine citrate or matching placebo daily until term corrected age. The frequency of intermittent hypoxaemia (events/ hour where oxygen saturation concentration is $\geq 10 \%$ below baseline for $\leq 2 \mathrm{~min}$ ) will be assessed with overnight oximetry at baseline, 2 weeks after randomisation (primary outcome) and at term corrected age. Growth will be measured at these timepoints, and effects on feeding and sleeping will be assessed by parental report. Data will be analysed using generalised linear mixed models.

Ethics and dissemination This trial has been approved by the Health and Disability Ethics Committees of New Zealand (reference 18/NTA/129) and the local institutional research review committees. Findings will be disseminated to peer-reviewed journals to clinicians and researchers at local and international conferences and to the public. The findings of the trial will inform the design of a large multicentre trial of prophylactic caffeine in late preterm infants, by indicating the most appropriate dose to use and providing information on feasibility.

Trial registration number ACTRN12618001745235;

Pre-results.

\section{INTRODUCTION}

Late preterm infants are those born between 34 weeks and 36 weeks and 6 days' gestation. ${ }^{1}$
Strengths and limitations of this study

- This study seeks to address the rates of neurodevelopmental impairment among late preterm infants by investigating the optimal dose of caffeine, as a potential primary neuroprotective strategy.

- This is the first randomised placebo-controlled trial of four different doses of caffeine for the prevention of intermittent hypoxaemia in late preterm infants.

- A strength of the trial is that both clinicians and parents will be blinded to treatment allocation with all groups receiving the same volume of an identicalappearing masked suspension.

- The success of the trial depends on high compliance of administration of study medication by caregivers, which will be monitored by intermittent measurement of study bottle contents and infant salivary caffeine concentrations.

- Future studies will be required to determine if caffeine reduces neurodevelopmental impairment in late preterm infants, based on the optimal dose determined by this trial.

They form the largest group within the preterm population, accounting for $68 \%$ of all preterm births or $5 \%$ of all births in New Zealand $^{2}$ and $7 \%$ of all births in the USA. ${ }^{3}$ Late preterm infants are physiologically and metabolically immature ${ }^{1}$ and have a higher risk of morbidity and mortality in the neonatal period than full-term infants. ${ }^{4}$ They are more likely than full-term infants to have delayed establishment of oral feeding, temperature instability, hypoglycaemia, jaundice and respiratory distress and to undergo investigation for sepsis. ${ }^{5}$ Despite these risks, their size and weight mean they are often managed in a similar manner to full-term infants and cared for on postnatal wards rather than in neonatal units ${ }^{6}$ and are not treated with the routine prophylactic interventions such as caffeine, nutritional supplements and probiotics that 


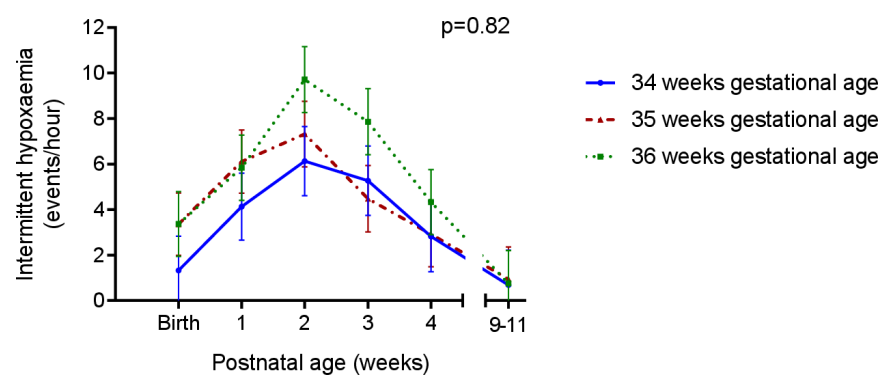

Figure 1 Rate of intermittent hypoxaemia in late preterm infants in the 9-11 weeks following birth; adapted from Williams et al. ${ }^{10}$

are common practice in very and extremely preterm infants.

Apnoea of prematurity are prolonged pauses in breathing, of $20 \mathrm{~s}$ or more, which may cause a reduction in the oxygen saturation and bradycardia, and are associated with an increased incidence of brain injury ${ }^{7}$ and neurodevelopmental impairment. ${ }^{8}$ Late preterm infants experience apnoea of prematurity, although less frequently than in very preterm infants. ${ }^{9}$ Recently, we have demonstrated that late preterm infants have frequent episodes of intermittent hypoxaemia, ${ }^{10}$ transient repetitive decreases in oxygen saturation not associated with apnoea, but potentially causing similar organ hypoxia. In late preterm infants, the frequency of intermittent hypoxaemia peaks at 2 weeks' postnatal age, before reducing to baseline levels at term corrected age (figure 1). ${ }^{10}$

Studies in adults have consistently shown that even brief exposure to hypoxia, whether from high altitude ${ }^{11}$ or carbon monoxide poisoning, ${ }^{12}$ can have long-term adverse effects on cognition. Even small changes in oxygen saturations in the neonatal period have been shown to significantly affect survival and neurodevelopment of very preterm infants. ${ }^{13-15}$ Intermittent hypoxaemia is associated with altered brain development in neonatal mice ${ }^{16}$ and reduced cognition and behavioural deficits in neonatal rats. ${ }^{17}$ In humans, transient intermittent hypoxaemic events are associated with poor neurodevelopmental outcomes in extremely preterm infants ${ }^{18}$ and in children with sleep-disordered breathing ${ }^{19}$ and congenital heart disease. ${ }^{20}$

Caffeine is a respiratory stimulant that is effective in the prevention and treatment of apnoea of prematurity and intermittent hypoxaemia and also reduces the incidence of chronic lung disease, cerebral palsy and cognitive delay in very preterm infants. ${ }^{21-23}$ Follow-up to 11 years of age has recently shown that caffeine treatment reduces the risk of motor dysfunction by a third infants born very preterm. ${ }^{24}{ }^{25}$ While some of the long-term beneficial effects of caffeine may be due to its effect in reducing the incidence of bronchopulmonary dysplasia, ${ }^{26}$ there is also benefit from reducing the amount of time that infants are hypoxic, independent of the effect on bronchopulmonary dysplasia. ${ }^{27}$ Thus, caffeine has become the standard of care for very preterm infants and is in widespread use in neonatal units around the world as one of the few neonatal treatments that has been proven to have longterm neurodevelopmental benefit and also to be very well tolerated.

In the longer term, late preterm infants are more likely to be diagnosed with cerebral palsy, ${ }^{28}{ }^{29}$ developmental delay, ${ }^{3031}$ cognitive impairment ${ }^{32-34}$ and behavioural disorders $^{35}$ compared with their term-born peers. However, few studies have investigated interventions to improve the neurodevelopmental outcomes of late preterm infants. As late preterm infants have an increase in hypoxaemic events compared with term infants, hypoxaemic events are associated with poor neurodevelopmental outcomes, it is possible that caffeine, an intervention that reduces hypoxaemic events and has already been shown to improve long-term outcomes in extremely and very preterm infants, may be effective at improving outcomes in late preterm infants.

In adults, most caffeine metabolism is via cytochrome P450 1A2 in the liver. ${ }^{36}$ However, in newborn preterm infants, hepatic metabolism of caffeine is almost absent, and most caffeine is eliminated via the kidneys, which are also immature. Therefore, caffeine elimination is slow in extremely preterm infants, and the half-life of caffeine is long. With increasing postconceptial age, the elimination of caffeine increases, ${ }^{3738}$ and larger doses may be needed to maintain a therapeutic effect. However, the pharmacokinetic studies of caffeine in preterm infants to date have been done to treat apnoea in very preterm infants, rather than to treat intermittent hypoxaemia in late preterm infants. ${ }^{39}$

There is a wide range in the dose of caffeine citrate given to extremely preterm infants, from daily doses of $5 \mathrm{mg} / \mathrm{kg}^{22}$ to $20 \mathrm{mg} / \mathrm{kg} .{ }^{40}$ The Caffeine for Apnoea of Prematurity trial used a dose of $5 \mathrm{mg} / \mathrm{kg}$, which could be increased to $10 \mathrm{mg} / \mathrm{kg}$ if necessary to control apnoea of prematurity. ${ }^{22}$ The trial by Rhein et al found that in very preterm infants, $6 \mathrm{mg} / \mathrm{kg}$ of caffeine citrate reduced intermittent hypoxaemia at 35 weeks' and 36 weeks' postmenstrual age, but not after 36 weeks' postmenstrual age. ${ }^{41}$ The authors hypothesised that this may have been due to an insufficient dose as the infants matured. Therefore, the most effective dose of caffeine to treat intermittent hypoxaemia in late preterm infants is unknown.

In very preterm infants, caffeine is usually well tolerated, but occasionally infants on caffeine develop tachycardia and feed intolerance. ${ }^{40}$ Caffeine also causes reduced neonatal weight gain compared with placebo, ${ }^{22}$ and in ventilated preterm infants, a higher dose of caffeine citrate $(20 \mathrm{mg} / \mathrm{kg})$ leads to reduced weight gain compared with a low dose $(5 \mathrm{mg} / \mathrm{kg}) .{ }^{40}$ As in adults, infants on caffeine can develop irritability, sleeplessness and gastrointestinal disturbance. For caffeine to be used as a prophylactic medication in a large number of late preterm infants, it will need to be prescribed at a dose that has a low risk of significant side effects.

We are therefore undertaking the Latte Dosage Trial, a randomised, placebo-controlled dosage trial, to determine the most effective and best-tolerated dose of oral 
caffeine citrate to reduce intermittent hypoxaemia in late preterm infants.

\section{Aim}

To determine the most effective and best-tolerated dose of caffeine citrate to reduce intermittent hypoxaemia in late preterm infants.

\section{Hypothesis}

Caffeine citrate will reduce the frequency of intermittent hypoxaemia in late preterm infants in a dose-dependant manner.

\section{METHODS AND ANALYSIS \\ Study design}

The Latte Dosage Trial is a phase IIB, double-blind, five-arm, parallel, randomised controlled trial to compare the effect of four different doses of oral caffeine citrate versus placebo on the frequency of intermittent hypoxaemia in late preterm infants.

\section{Recruitment and randomisation}

Participants will be recruited by trial investigators or study nurses/midwives within 72 hours of birth from the neonatal unit and postnatal wards at Auckland City and Middlemore Hospitals in Auckland, New Zealand. Following written informed consent and enrolment, trial participation may occur in hospital, at a primary maternity unit or at home, as the patient's clinical care dictates. Eligible participants are those infants born between 34 weeks and 36 weeks' and 6 days gestation without contradiction to caffeine treatment, with the following exclusions:

- Major congenital abnormality.

- Minor congenital abnormality likely to affect respiration, growth or development.

- Previous caffeine treatment.

- Renal or hepatic impairment.

- Tachyarrhythmia.

- Seizures.

- Hypoxic ischaemic encephalopathy.

- Residing outside of the Auckland region.

Infants will be assigned randomly via an internet randomisation service (Clinical Data Research Hub, Liggins Institute, University of Auckland) to receive either daily caffeine citrate $5 \mathrm{mg} / \mathrm{kg}, 10 \mathrm{mg} / \mathrm{kg}, 15 \mathrm{mg} / \mathrm{kg}, 20 \mathrm{mg} / \mathrm{kg}$ or placebo. The allocation sequence will be generated by the study statistician, with 1:1:1:1:1 allocation stratified by study site and gestational age at birth (34, 35 or 36 weeks)

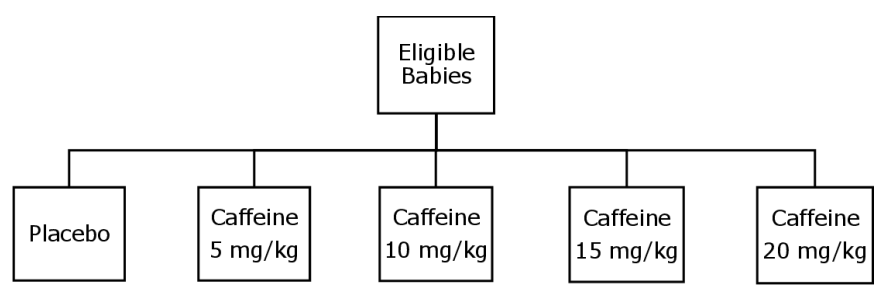

Figure 2 Flow diagram of randomisation schedule. (figure 2) using variable block sizes, with infants from multiple births being randomised to the same treatment group.

Different concentrations of the caffeine citrate $(5 \mathrm{mg} /$ $\mathrm{mL}, 10 \mathrm{mg} / \mathrm{mL}, 15 \mathrm{mg} / \mathrm{mL}$ and $20 \mathrm{mg} / \mathrm{mL}$ ) will be prepared in identical bottles to the placebo so that all infants receive the same dose volume $(2 \mathrm{~mL} / \mathrm{kg}$ loading dose followed by $1 \mathrm{~mL} / \mathrm{kg}$, once a day). Bottles will be labelled in randomisation blocks using a lettering system that will change halfway through the study in order to maintain concealment from study personnel.

\section{Study intervention}

The infant will be given an enteral loading dose of the study drug $(10 \mathrm{mg} / \mathrm{kg}, 20 \mathrm{mg} / \mathrm{kg}, 30 \mathrm{mg} / \mathrm{kg}$ or $40 \mathrm{mg} / \mathrm{kg}$ of caffeine citrate or water) in the morning after baseline oximetry (ie, prior to the infant reaching 96 hours of age), followed by a daily dose each morning ( $5 \mathrm{mg}$ / $\mathrm{kg}, 10 \mathrm{mg} / \mathrm{kg}, 15 \mathrm{mg} / \mathrm{kg}$ or $20 \mathrm{mg} / \mathrm{kg}$ of caffeine citrate or placebo) until term equivalent age (40 weeks' postmenstrual age). The dose will be recalculated weekly for weight after the infant has regained birth weight using the weight recorded by study staff at 2 weeks after randomisation and those recorded by usual care providers between 2 weeks' and term corrected age. The study drug will be given via a nasogastric tube for infants with a tube in situ and orally for infants who do not require a nasogastric tube. Infants who are not able to tolerate enteral medications will have the study drug withheld until they are able to tolerate enteral intake.

Compliance will be assessed by measurement of study medication remaining in the bottle. At the 2-week visit, study staff will collect the initial bottle(s) issued at the start of the study and replace it with a new bottle(s), which will in turn be collected at the final visit. Liquid remaining in the bottle on each occasion will be measured and compared with the expected volume to assess compliance. Good compliance will be defined as $\geq 80 \%$ of the expected volume having been removed from the bottle. At the final visit, parents will be asked which treatment they think their infant received to assess the adequacy of blinding.

Apart from the study intervention and associated assessments, all other clinical cares, including the decision on when to discharge participants from the hospital and/or primary birthing units, will continue to be provided by the local clinical team, in accordance with usual guidelines and practices. Should an infant participating in the study require treatment for apnoea or intermittent hypoxaemia, clinicians will be encouraged to use oxygen or positive pressure ventilation as first-line treatments. If necessary, a loading dose of caffeine citrate may be given. If ongoing treatment with caffeine is necessary for the opinion of the treating clinician, they can discuss the option of partially unblinding the infant (caffeine or placebo) with the site principal investigator. If unblinding is required, information on the allocation of the participant will be communicated by the data management 
team to the treating clinician or pharmacist (who may inform the parents if requested), with the research team remaining blinded. Clinical open-label use of caffeine will be recorded. Unblinded infants will remain in the study unless parents request withdrawal, with infants analysed on an intention-to-treat basis.

\section{Outcomes}

The primary outcome for this study is the frequency of intermittent hypoxaemia (events/hour, defined as a brief transient fall in oxygen saturation concentration $\geq 10 \%$ below baseline) on overnight oximetry, 2 weeks after randomisation. Events longer than $2 \mathrm{~min}$ are considered a change in baseline rather than a transient desaturation event. Transient intermittent hypoxaemic events, if frequent or severe, are thought to have neurocognitive effects as significant as prolonged hypoxaemia. ${ }^{20} 42$ Although a $3 \%$ threshold is used in polysomnography to define desaturation events, a definition of $10 \%$ is commonly used in the neonatal literature. In addition, due to the variability of events, we considered a $10 \%$ threshold more repeatable and reliable than a $3 \%$ threshold for defining events.

Secondary outcomes include:

- Respiratory: frequency of intermittent hypoxaemia on overnight oximetry at term equivalent age; mean overnight oxygen saturation at 2 weeks and term equivalent age; use of respiratory support, including oxygen, until term equivalent age.

- Growth: growth velocity from birth to term equivalent age for weight gain, length and head circumference; failure to regain birth weight by 2 weeks of age.
- Side effects: feed intolerance as reported by parents; ${ }^{43}$ duration of tube feeding; sleep and arousal as reported by parents (measured by subscale nine on the Infant Behaviour Questionnaire-Revised, modified for neonates ${ }^{44}$ ); tachycardia; study drug stopped due to presumed side effects; neonatal seizures requiring anticonvulsant treatment before 44 weeks postmenstrual age; neonatal or infant death.

- Maternal and infant salivary caffeine concentration at 2 weeks after randomisation. ${ }^{45}$

- Readmission to hospital until 44 weeks postmenstrual age or open-label caffeine use.

- Maternal caffeine intake at birth, 2 weeks and term corrected age and mental health (Edinburgh postnatal depression score) at birth and term corrected age. ${ }^{46}$

The timing of the study intervention and assessments is summarised in table 1 .

\section{Data collection methods}

Online data management services will be provided by the Clinical Data Research Hub (Liggins Institute, University of Auckland). Data collection will use the REDCap platform (Vanderbilt University) for clinical report forms, with password-protected secure servers used to store data.

\section{Pulse oximetry}

Overnight pulse oximetry (Rad 8, Masimo, Irvine, California, USA) will be recorded for a period of 12 hours from either foot at baseline, 2 weeks after randomisation (range 12-21 days) and at term corrected age (range $40-41$ weeks postmenstrual age) using a $2 \mathrm{~s}$ averaging

Table 1 Study intervention and assessment

\begin{tabular}{|c|c|c|c|c|c|c|}
\hline & Baseline & $\begin{array}{l}\text { Morning following } \\
\text { baseline oximetry }\end{array}$ & 1 week & 2 weeks & 3-5 weeks & $\begin{array}{l}\text { Term } \\
\text { equivalent } \\
\text { age }\end{array}$ \\
\hline Pulse oximetry & $x$ & & & $x$ & & $x$ \\
\hline Randomisation & $x$ & & & & & \\
\hline Loading dose & & $x$ & & & & \\
\hline Demographics, contacts & $x$ & & & & & \\
\hline Dose adjustment for weight & & & & $x$ & $x$ & \\
\hline Neonatal salivary caffeine concentration & & & & $x$ & & \\
\hline Maternal salivary caffeine concentration & & & & $x$ & & \\
\hline Drug diary & & $x$ & $\mathrm{X}$ & $x$ & $x$ & $x$ \\
\hline Compliance assessment & & & & $x$ & & $x$ \\
\hline \multicolumn{7}{|l|}{ Parental questionnaires: } \\
\hline $\begin{array}{l}\text { Maternal smoking in pregnancy and } \\
\text { household smoke exposure questionnaire }\end{array}$ & $x$ & & & & & \\
\hline Sleep questionnaire & & & & $x$ & & $x$ \\
\hline Feed tolerance questionnaire & & & & $x$ & & $x$ \\
\hline Maternal caffeine intake questionnaire & $\mathrm{x}$ & & & $\mathrm{x}$ & & $\mathrm{x}$ \\
\hline Edinburgh postnatal depression scale & $\mathrm{x}$ & & & & & $\mathrm{x}$ \\
\hline
\end{tabular}


time and $2 \mathrm{~s}$ resolution. Recordings will be conducted at home, in primary birthing units or at home as dictated by the clinical care requirements of the participants. Where recordings are conducted at home, parents will be visited the day that recording starts by a member of the research team. The oximeter will be set up, and the parents will receive instruction in attaching the probe to the baby's foot and be instructed to do this when placing the baby down to sleep in the evening. If necessary, the research team member may visit late in the day to apply the probe or provide support via a video call to ensure this is done correctly by parents. Unless clinically required, oximeters will be operated in sleep mode, with no displays or alarms. The oximetry recording will be downloaded with PROFOX oximetry software (V.Masimo 2011.27D, PROFOX Associates, Esconditso, California, USA) and edited to remove readings with poor signal or aberrant data. Only recordings with more than 6 hours will be included in the analysis, recordings with less than 6 hours of edited data will be repeated the following night.

\section{Anthropometry}

Weight, length and head circumference will be measured at study entry and at the 2-week and term visits, with birth weight and neonatal centiles calculated using Fenton-WHO growth charts for preterm infants, ${ }^{47}$ and growth velocity will be calculated between birth and term equivalent using an exponential model. ${ }^{48}$

\section{Salivary caffeine concentrations}

Two weeks after randomisation, a saliva sample will be collected from infants for assessment of caffeine concentration. Samples will be taken using a mouth swab prior to administration of the morning dose of trial medication. In 24 hours preceding this, mothers will be asked to collect three saliva samples by spitting into collection tubes at three predetermined time points during the day, with the mean of these three samples used to determine average daytime maternal salivary caffeine concentration. Collection of these samples will allow us to compare maternal and infant salivary caffeine concentrations to establish whether maternal caffeine intake contributes significantly to infant caffeine levels via breastfeeding or not and to help assess compliance with the study intervention.

\section{Questionnaires}

Mothers will complete questionnaires to provide demographic and contact details at enrolment and to assess smoking, infant feeding and sleeping, maternal caffeine intake and maternal mental health as detailed in table 1.

\section{Neonatal morbidity}

Information on neonatal morbidity, including supplemental oxygen, respiratory support and apnoea requiring stimulation, will be recorded from the neonatal record. Exposure to antenatal corticosteroids will be recorded.

\section{Discontinuation of intervention/ withdrawal}

The allocated treatment may be stopped at any time by the parents or the clinician caring for the infant if they feel that this is in the best interests of the infant, without formally withdrawing, in which case data collection will continue and results will be analysed on an intention-totreat basis.

Should a parent wish to withdraw from the study, they will have the option of:

1. Discontinuation of study drug, with continuation of collection of minimum outcome data.

2. Withdrawal from the study and discontinuation of further data collection, with data collected prior to withdrawal used.

3. Complete withdrawal from the study, with removal of previously collected data.

Patient and public involvement

The Latte Dosage Study methodology was discussed, developed and refined as part of the 2017 On-Track Network clinical trial development workshop that included consumer and Māori cultural advisor input. Perinatal consumer representatives provided advice and input into the development of the clinical trial protocol.

\section{Sample size}

Based on our previous study, ${ }^{10}$ we estimate a background mean (SD) frequency of 6.9 (3.4) episodes of intermittent hypoxaemia per hour at 2 weeks' postrandomisation. To detect a $50 \%$ reduction of 3.5 episodes per hour with $90 \%$ power, allowing for a $10 \%$ drop out rate and clustering of multiples with an intraclass correlation coefficient of 0.05 , we will require 24 infants in each of the five arms (total 120 infants), with two-sided alpha of 0.05 . Recruitment to the study started in February 2019 and is scheduled to conclude in December 2020.

\section{Data analysis}

The primary analysis will compare primary and secondary outcomes between groups using generalised linear mixed models with adjustment for gestational age at birth and site (fixed effects), non-independence of multiples (random effect) and pairwise comparisons between the different caffeine groups and between the caffeine groups and the placebo group using Dunnett's multiple comparison test. The selection of the optimal dose will be based on a combination of the dose with the greatest reduction of intermittent hypoxaemia with a minimum number of side effects and a pragmatic consideration of the ease of administration. Linear trends, such as growth, will be tested using orthogonal contrasts. In keeping with Consolidated Standards of Reporting Trial recommendations, ${ }^{49}$ baseline imbalance between babies in the randomised groups will not be formally tested. Edinburgh Postnatal Depression Scale scores will be adjusted for baseline values. Categorical data will be presented as number and per cent, and continuous data as mean and SD or median and IQR, as appropriate. Denominators will be given for 
all outcomes. Treatment effects will be presented as OR, count ratio, mean difference or ratio of geometric means (positively skewed data), as appropriate, with 95\% CIs. All tests will be two tailed, with $\mathrm{p}<0.05$ considered significant. The data will be analysed on an intention-to-treat basis.

The following secondary analyses will be performed:

- Compliance: a per-protocol analysis will be performed for the primary outcome that includes only those infants who were compliant with the study drug.

- Open-label caffeine treatment: a sensitivity analysis will be performed for the primary outcome that includes only those infants who did not receive additional open-label caffeine treatment.

- Maternal caffeine: an exploratory analysis will be performed on the effect of maternal caffeine intake on the primary outcome by performing additional adjustments for maternal caffeine intake from the questionnaire and maternal salivary caffeine concentration. For infants who are fully formula fed, infant caffeine exposure to maternal caffeine intake will be assumed to be zero.

An independent data monitoring committee will review trial data after enrolment of 60 infants to the trial. The data monitoring committee provides advice to the trial steering group on any modifications that may be required. There are no formal stopping guidelines.

\section{ETHICS AND DISSEMINATION}

Ethical approval has been obtained from the Health and Disability Ethics Committees of New Zealand (reference 18/NTA/129) and by the local institutional research review committees for each centre. The trial is registered with the Australian New Zealand Clinical Trials Registry from 24 October 2018.

The results of the trial will be published in an international peer-reviewed journal and disseminated via presentations at local and international conferences to researchers and clinicians. A lay summary of the research findings will be made available to those parents who indicated a wish to receive these on their consent forms.

\section{DISCUSSION}

Late preterm infants experience higher rates of intermittent hypoxaemia than their term-born peers and have poorer long-term neurodevelopmental outcomes. ${ }^{28-35}$ Caffeine is well established as a treatment for apnoea of prematurity in very and extremely preterm infants and improves long-term neurodevelopmental outcomes in these infants..$^{21} 5051$ Caffeine use in late preterm infants may also reduce episodes of intermittent hypoxaemia and improve long-term outcomes for these infants. As late preterm infants make up the majority of preterm infants, interventions that improve long-term outcomes in this population are likely to have the greatest public health impact in terms of interventions for preterm infants. ${ }^{52}$
The Latte Dosage Trial seeks to establish the most effective and best-tolerated dose of caffeine citrate for the prevention of intermittent hypoxaemia in late preterm infants. It is the first trial to investigate the use of caffeine, an inexpensive medication already widely used in neonatal care, for this indication. Data from the Latte Dosage Trial will be used to inform the development of a large-scale, multicentre trial investigating the efficacy of caffeine treatment in late preterm infants in preventing neurodevelopmental impairment by indicating the most appropriate dose to use and providing information on feasibility.

\section{Author affiliations}

${ }^{1}$ Department of Paediatrics: Child and Youth Health, The University of Auckland, Auckland, New Zealand

${ }^{2}$ Newborn Services, Starship Children's Health, Auckland District Health Board, Auckland, New Zealand

${ }^{3}$ Liggins Institute, The University of Auckland, Auckland, New Zealand

${ }^{4}$ Kidz First Neonatal Care, Counties Manukau Health, Auckland, New Zealand

${ }^{5}$ Paediatrics Respiratory Services, Starship Children's Health, Auckland District Health Board, Auckland, New Zealand

Acknowledgements Brian Darlow and Members of the On-Track network for assistance in developing and refining the study design. Sarah Phillipsen, Sabine Huth, Lisa Mravicich and Florella Keen for assistance in setting up the trial. Sara Hanning and Trusha Purohit for advice on caffeine testing and development of the caffeine assay. Alana Cavadino for statistical advice.

Contributors JMA conceived and developed the study design, drafted the original study protocol, approved the final study protocol and reviewed the article for publication. EAO contributed to the study design, approved the final version of the study protocol and drafted the article for publication. CJDM contributed to the study design, approved the final version of the study protocol and reviewed the article for publication. DGM contributed to the study design, approved the final version of the study protocol and reviewed the article for publication.

Funding This work is supported by the Health Research Council of New Zealand: grant number 18/613.

\section{Competing interests None declared.}

Patient and public involvement Patients and/or the public were involved in the design, or conduct, or reporting, or dissemination plans of this research. Refer to the Methods section for further details.

Patient consent for publication Not required.

Provenance and peer review Not commissioned; externally peer reviewed.

Open access This is an open access article distributed in accordance with the Creative Commons Attribution Non Commercial (CC BY-NC 4.0) license, which permits others to distribute, remix, adapt, build upon this work non-commercially, and license their derivative works on different terms, provided the original work is properly cited, appropriate credit is given, any changes made indicated, and the use is non-commercial. See: http://creativecommons.org/licenses/by-nc/4.0/.

\section{ORCID iDs}

Elizabeth Anne Oliphant http://orcid.org/0000-0002-3660-4127

Jane Marie Alsweiler http://orcid.org/0000-0002-0874-6654

\section{REFERENCES}

1 Engle WA, Tomashek KM, Wallman C, et al. "Late-preterm" infants: a population at risk. Pediatrics 2007;120:1390-401.

2 Ministry of Health. Report on Maternity 2017 - tables. Wellington, 2019. Available: https://www.health.govt.nz/publication/reportmaternity-2017 [Accessed 8 Jul 2019].

3 Martin JA, Hamilton BE, Osterman MJK, et al. Births: final data for 2017, 2017. Available: https://www.cdc.gov/nchs/data_access/ Vitalstatsonline.htm

4 Mclntire DD, Leveno KJ. Neonatal mortality and morbidity rates in late preterm births compared with births at term. Obstet Gynecol 2008;111:35-41. 
5 Wang ML, Dorer DJ, Fleming MP, et al. Clinical outcomes of nearterm infants. Pediatrics 2004;114:372-6.

6 Boyle EM, Johnson S, Manktelow B, et al. Neonatal outcomes and delivery of care for infants born late preterm or moderately preterm: a prospective population-based study. Arch Dis Child Fetal Neonatal Ed 2015;100:F479-85.

7 Butcher-Puech MC, Henderson-Smart DJ, Holley D, et al. Relation between apnoea duration and type and neurological status of preterm infants. Arch Dis Child 1985;60:953-8.

8 Janvier A, Khairy M, Kokkotis A, et al. Apnea is associated with neurodevelopmental impairment in very low birth weight infants. $J$ Perinatol 2004;24:763-8.

9 Henderson-Smart DJ. The effect of gestational age on the incidence and duration of recurrent apnoea in newborn babies. Aust Paediatr $J$ 1981;17:273-6.

10 Williams LZJ, McNamara D, Alsweiler JM. Intermittent hypoxemia in infants born late preterm: a prospective cohort observational study. $J$ Pediatr 2019;204:89-95.

11 Bahrke MS, Shukitt-Hale B. Effects of altitude on mood, behaviour and cognitive functioning. A review. Sports Med 1993;16:97-125.

12 Weaver LK, Hopkins RO, Chan KJ, et al. Hyperbaric oxygen for acute carbon monoxide poisoning. $N$ Engl J Med 2002;347:1057-67.

13 Saugstad OD, Aune D. Optimal oxygenation of extremely low birth weight infants: a meta-analysis and systematic review of the oxygen saturation target studies. Neonatology 2014;105:55-63.

14 SUPPORT Study Group of the Eunice Kennedy Shriver NICHD Neonatal Research Network, Carlo WA, Finer NN, et al. Target ranges of oxygen saturation in extremely preterm infants. $N$ Engl $J$ Med 2010;362:1959-69.

15 Stenson B, Brocklehurst P, Tarnow-Mordi W, et al. Increased 36week survival with high oxygen saturation target in extremely preterm infants. N Engl J Med 2011;364:1680-2.

16 Kanaan A, Farahani R, Douglas RM, et al. Effect of chronic continuous or intermittent hypoxia and reoxygenation on cerebral capillary density and myelination. Am J Physiol Regul Integr Comp Physiol 2006;290:R1105-14.

17 Row BW, Kheirandish L, Neville JJ, et al. Impaired spatial learning and hyperactivity in developing rats exposed to intermittent hypoxia. Pediatr Res 2002;52:449-53.

18 Poets CF, Roberts RS, Schmidt B, et al. Association between intermittent hypoxemia or bradycardia and late death or disability in extremely preterm infants. JAMA 2015;314:595-603.

19 Ali NJ, Pitson D, Stradling JR. Sleep disordered breathing: effects of adenotonsillectomy on behaviour and psychological functioning. Eur J Pediatr 1996;155:56-62.

20 Bass JL, Corwin M, Gozal D, et al. The effect of chronic or intermittent hypoxia on cognition in childhood: a review of the evidence. Pediatrics 2004;114:805-16.

21 Schmidt B, Roberts RS, Davis P, et al. Long-Term effects of caffeine therapy for apnea of prematurity. $N$ Engl $J$ Med 2007;357:1893-902.

22 Schmidt B, Roberts RS, Davis P, et al. Caffeine therapy for apnea of prematurity. N Engl J Med Overseas Ed 2006;354:2112-21.

23 McNamara DG, Nixon GM, Anderson BJ. Methylxanthines for the treatment of apnea associated with bronchiolitis and anesthesia. Paediatr Anaesth 2004;14:541-50.

24 Schmidt B, Roberts RS, Anderson PJ, et al. Academic performance, motor function, and behavior 11 years after neonatal caffeine citrate therapy for apnea of prematurity: an 11-year follow-up of the cap randomized clinical trial. JAMA Pediatr 2017;171:564.

25 Doyle LW, Ranganathan S, Cheong JLY. Neonatal caffeine treatment and respiratory function at 11 years in children under $1,251 \mathrm{G}$ at birth. Am J Respir Crit Care Med 2017:196:1318-24

26 Davis PG, Schmidt B, Roberts RS, et al. Caffeine for apnea of prematurity trial: benefits may vary in subgroups. $J$ Pediatr 2010;156:382-7.

27 Doyle LW, Cheong J, Hunt RW, et al. Caffeine and brain development in very preterm infants. Ann Neurol 2010;68:734-42.

28 Moster D, Lie RT, Markestad T. Long-Term medical and social consequences of preterm birth. N Engl J Med 2008;359:262-73.

29 Odd DE, Lingam R, Emond A, et al. Movement outcomes of infants born moderate and late preterm. Acta Paediatr 2013;102:876-82.
30 Darlow BA, Horwood LJ, Wynn-Williams MB, et al. Admissions of all gestations to a regional neonatal unit versus controls: 2-year outcome. J Paediatr Child Health 2009;45:187-93.

31 Woythaler MA, McCormick MC, Smith VC. Late preterm infants have worse 24-month neurodevelopmental outcomes than term infants. Pediatrics 2011;127:e622-9.

32 Talge NM, Holzman C, Wang J, et al. Late-preterm birth and its association with cognitive and socioemotional outcomes at 6 years of age. Pediatrics 2010;126:1124-31.

33 Quigley MA, Poulsen G, Boyle E, et al. Early term and late preterm birth are associated with poorer school performance at age 5 years: a cohort study. Arch Dis Child Fetal Neonatal Ed 2012;97:F167-73.

34 Heinonen K, Eriksson JG, Lahti J, et al. Late preterm birth and neurocognitive performance in late adulthood: a birth cohort study. Pediatrics 2015;135:e818-25.

35 Huddy CL, Johnson A, Hope PL. Educational and behavioural problems in babies of 32-35 weeks gestation. Arch Dis Child Fetal Neonatal Ed 2001;85:23F-8.

36 Anderson BJ, Gunn TR, Holford NH, et al. Caffeine overdose in a premature infant: clinical course and pharmacokinetics. Anaesth Intensive Care 1999;27:307-11.

37 Le Guennec JC, Billon B, Paré C. Maturational changes of caffeine concentrations and disposition in infancy during maintenance therapy for apnea of prematurity: influence of gestational age, hepatic disease, and breast-feeding. Pediatrics 1985;76:834-40.

38 Falcão AC, Fernández de Gatta MM, Delgado Iribarnegaray MF, et al. Population pharmacokinetics of caffeine in premature neonates. Eur J Clin Pharmacol 1997;52:211-7.

39 Thomson AH, Kerr S, Wright S. Population pharmacokinetics of caffeine in neonates and young infants. Ther Drug Monit 1996;18:245-53.

40 Steer P, Flenady V, Shearman A, et al. High dose caffeine citrate for extubation of preterm infants: a randomised controlled trial. Arch Dis Child Fetal Neonatal Ed 2004:89:F499-503.

41 Rhein LM, Dobson NR, Darnall RA, et al. Effects of caffeine on intermittent hypoxia in infants born prematurely: a randomized clinical trial. JAMA Pediatr 2014;168:250-7.

42 Blunden SL, Beebe DW. The contribution of intermittent hypoxia, sleep debt and sleep disruption to daytime performance deficits in children: consideration of respiratory and non-respiratory sleep disorders. Sleep Med Rev 2006;10:109-18.

43 Kleinman L, Rothman M, Strauss R, et al. The infant gastroesophageal reflux questionnaire revised: development and validation as an evaluative instrument. Clin Gastroenterol Hepatol 2006;4:588-96.

44 Gartstein MA, Rothbart MK. Studying infant temperament via the revised infant behavior questionnaire. Infant Behav Dev 2003:26:64-86

45 Dobson NR, Liu X, Rhein LM, et al. Salivary caffeine concentrations are comparable to plasma concentrations in preterm infants receiving extended caffeine therapy. Br J Clin Pharmacol 2016;82:754-61.

46 Cox JL, Holden JM, Sagovsky R. Detection of postnatal depression. development of the 10-item Edinburgh postnatal depression scale. Br J Psychiatry 1987;150:782-6.

47 Fenton TR, Kim JH. A systematic review and meta-analysis to revise the Fenton growth chart for preterm infants. BMC Pediatr 2013;13:59.

48 Patel AL, Engstrom JL, Meier PP, et al. Calculating postnatal growth velocity in very low birth weight (VLBW) premature infants. J Perinatol 2009;29:618-22.

49 Moher D, Hopewell S, Schulz KF, et al. Consort 2010 explanation and elaboration: updated guidelines for reporting parallel group randomised trials. J Clin Epidemiol 2010;63:e1-37.

50 Schmidt B, Anderson PJ, Doyle LW, et al. Survival without disability to age 5 years after neonatal caffeine therapy for apnea of prematurity. JAMA 2012;307:275.

51 Mürner-Lavanchy IM, Doyle LW, Schmidt B, et al. Neurobehavioral outcomes 11 years after neonatal caffeine therapy for apnea of prematurity. Pediatrics 2018:141:e20174047.

52 March of Dimes. The Partnership for Maternal Newborn and Child Health, Save the Children, et al. Born too soon: the global action report on preterm birth. Geneva, 2012. http://whqlibdoc.who.int/ publications/2012/9789241503433_eng.pdf 
Correction: (Rad 8)Caffeine prophylaxis to improve

intermittent hypoxaemia in infants born late preterm: a randomised controlled dosage trial (Latte Dosage Trial)

Oliphant EA, McKinlay CJD, McNamara DG, et al. (Rad 8) Caffeine prophylaxis to improve intermittent hypoxaemia in infants born late preterm: a randomised controlled dosage trial (Latte Dosage Trial). BMJ Open 2020;10:e038271. doi: 10.1136/ bmjopen-2020-038271.

This article was previously published with an error.

There was a typographical error in the title. The correct title is:

Caffeine prophylaxis to improve intermittent hypoxaemia in infants born late preterm: a randomised controlled dosage trial (Latte Dosage Trial)

Open access This is an open access article distributed in accordance with the Creative Commons Attribution Non Commercial (CC BY-NC 4.0) license, which permits others to distribute, remix, adapt, build upon this work non-commercially, and license their derivative works on different terms, provided the original work is properly cited, appropriate credit is given, any changes made indicated, and the use is non-commercial. See: http://creativecommons.org/licenses/by-nc/4.0/.

(C) Author(s) (or their employer(s)) 2020. Re-use permitted under CC BY-NC. No commercial re-use. See rights and permissions. Published by BMJ.

BMJ Open 2020;10:e038271corr1. doi:10.1136/bmjopen-2020-038271corr1

D) Check for updates 